\title{
Effect of the National Health Insurance Scheme on Healthcare Utilization and Out-of-Pocket Payment: Evidence from GLSS 7
}

\author{
Adu Owusu Sarkodie ${ }^{1 凶}$
}

The Ghana National Health Insurance Scheme (NHIS) was established in 2003, Act, 2003 (Act 650), but was later replaced with the National Health Insurance Act, 2012 (Act 852) to get rid of the then "cash and carry" system of paying for healthcare. The aim of the scheme was to reduce the cost of healthcare provision and increase access to healthcare. This paper investigates the effect of the National Health Insurance Scheme (NHIS) on healthcare utilization and out-of-pocket payment, from the providers' perspective. The study uses data from the seventh round of the Ghana Living Standards Survey (GLSS 7) conducted in 2016/2017 and employs the estimation method of Propensity Score Matching (PSM). The findings are that enrollment onto Ghana's National Health Insurance Scheme (NHIS) increases healthcare utilization by $26 \%$ and decreases out-of-pocket payment by $4 \%$. However, about $48 \%$ of the population are still not enrolled, citing various reasons. Even those who enrolled, about $30 \%$ had dropped out for several reasons. The study identifies age, income, education, sex, and location of residence as the main determinants of enrolling onto the NHIS. I show that the National Health Insurance Scheme increases healthcare utilization and reduces out-of-pocket payment in Ghana. A number of Ghanaians have either not registered or registered but have stopped enrolling citing no money, no need for NHIS, and no confidence in the system' as reasons. Any policy to invigorate the public confidence in NHIS and increases enrollment should be targeted at the young, poor, less educated, males, and rural dwellers.

\section{Introduction}

he Universal Health Coverage states that all persons should have access to healthcare they need without any difficulty in paying for them (WHO, 2013). Owing to the enormous pressure out-of-pocket payment puts on the incomes of households in their attempt to seek healthcare, different types of strategies for easing the payment need to be examined if Ghana is to achieve the Universal Health Coverage target (Blanchet et al., 2012; Witter and Garshong, 2009). Health Insurance seems to be very attractive and is gaining more and more attention in developing countries because it serves as a means of improving healthcare utilization and household protection against impoverishment, which results from out-of-pocket (Blanchet et al., 2012). The World Health Organization recognizes health insurance as a promising means to attain universal health coverage (WHO, 2013; Spaan et al., 2012).

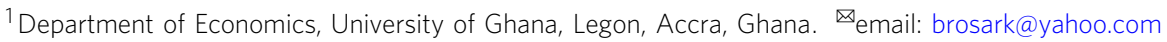


Ghana has a history when it comes to healthcare financing. The "cash and carry" system that existed in the past posed serious threats to healthcare utilization. It was a "pay-before-treatment" situation. Patients who could not pay for healthcare were either denied treatment, and even if they were lucky to receive treatment but could still not pay, they were detained at the health facilities (Nketiah-Amponsah and Sarkodie, 2014). Upon winning the December 2000 general elections, the New Patriotic Party fulfilled its promise by establishing the National Health Insurance Scheme (NHIS) in 2003 (Act 650). As at February, 2020, there were about 12 million active members representing $40 \%$ of the Ghanaian population. Out of this number, about $34.1 \%$ were made up of those from the informal sector who are the only premium-paying subscribers. This is because for workers in the formal sector, their contributions are deducted from source (from their salaries) being the $2.5 \%$ SSNIT contribution.

Existing literature confirms that enrollment onto the NHIS has increased healthcare utilization for both out-patient and inpatient cases and reduced out-of-pocket payment either in Ghana or in other parts of the world (Blanchet et al., 2012; Boakye, 2016; Nketiah-Amponsah and Sarkodie, 2014; Dong, 2011; Xiao, 2011). The above statement is for the general case. Even in specific reasons, other studies have again confirmed the positive effect of health insurance on maternal healthcare (Owoo and Lambon-Quayefio, 2013). For instance, Wang et al. (2017) adopted four measures of maternal healthcare utilization: making at least one antennal care; making four or more antenatal care visits; initiating antenatal care within the first trimester; and giving birth in a health facility. It was concluded that women in Ghana and Indonesia (80\%) have had four or more visits than Rwanda (36\%). The percentage of women covered in any form of health insurance is highest in Rwanda (73.1), followed by Ghana (40.1), and Indonesia (36.3). Although national health insurance schemes are designed to help the poor access healthcare, coverage has been found to be high among the rich, especially Ghana and Rwanda, but less pronounced in Indonesia (Saksena et al., 2010). In Ghana, women with access to health insurance are about 8 and 1 percentage points more likely to utilize public and private respectively, compared to home delivery. Women in urban areas are 16 percentage points more (Nketiah-Amponsah and Arthur, 2013).

Parental enrollment does not only increase their healthcare utilization for themselves but also for their children (GajateGarrido and Ahiadeke, 2012; Gajate-Garrido and Ahiadeke, 2015). Lambon-Quayefio and Owoo (2017) employed probit and propensity score matching to establish that active membership in the National Health Insurance Scheme (NHIS) has some influence on neonatal deaths in Ghana. Other studies have indicated that the uninsured person has worse health outcomes (Card et al., 2012; Jutting, 2001; Ibiwoye and Adeleke, 2007). Enrolling onto a health insurance is likely to reduce out-of-pocket payment (Sekyi and Domanban, 2012).

When discussing the effect of health insurance on healthcare utilization, care must be taken about the possible presence of adverse selection and morale hazards (Duku et al., 2016). Health insurance has a far more reaching benefits than just healthcare utilization. It also helps in resource mobilization, financial protection, healthcare utilization, healthcare quality, social inclusion, and community empowerment (Spaan et al., 2012).

This study fills in the gap by emphasizing the importance of the National Health Insurance Scheme on access to healthcare. While other papers concentrated on the effect of the National Health Insurance Scheme on the purpose of use of healthcare (like for antenatal purposes, maternal health, etc.), this paper gives more attention to estimating how enrollment onto the National Health Insurance Scheme affects the decision to seek healthcare and also the choice of a particular type of healthcare provider. In other words, estimation is done from the provider's perspective. The study attempts to find out why close to half of the Ghanaian population are still not enrolled and even those who are enrolled, some of them have dropped out. It also identifies the main determinants of enrolling onto the NHIS. The study also uses a more recent nationally representative data from the GLSS 7.

\section{Ghana's healthcare sector}

In the sixteenth century, Ghanaians sought healthcare from traditional herbalist. Though traditional herbalists were very successful in their healthcare delivery in Ghana, the premier traditional healers stressed the need to combine herbs with modern medicine to offer healthcare. Sooner than later, it was not until the eighteenth century when missionaries to the then Gold Coast established modern health facilities to deliver healthcare services to the citizens. Until now, missionary hospitals and health centers are still very relevant in healthcare delivery (Blanchet et al., 2012).

Ghana's health system is one of the most advanced health systems in Africa. Government of Ghana (GoG) adopted the primary healthcare strategy in the 1970s to achieve "Health for All" by the year 2000. Private health facilities have played important roles in achieving such successes. Private health providers account for about $50 \%$ of all health facilities in the country. In the year 2013, about 3822 facilities were credentialed by the National Health Insurance Authority (NHIA). Out of this number, 1197 were CHPS compound representing 31.3\%. This was followed by 2075 public facilities (54.3), 1511 private facilities (39.5\%). Others included mission (5\%) and quasi-government ownership (1\%). The Traditional and Spiritual medicines still play complementary roles in providing healthcare (NHIA, 2013).

Government's expenditure on health as a percentage of total government expenditure is estimated at $11 \%$ (GSS, 2017). This is still less than the Abuja Declaration, where African countries pledged to spend $15 \%$ of their total expenditure on health. The sources of finance are Central government (56\%), Internally Generated Funds (IGF) (20.9\%), Credit Facility (10.3\%), Donor (9.3\%), Budget support (3.3\%), NHIA (0.2\%) (GSS, 2017).

In the pre-independence era, healthcare was virtually free since it was funded by the tax system. However, this was financially unsustainable in the times when the country was facing serious economic challenges, especially in the 1970s and 1980s. Public spending on health declined. Between 1980 and 1990, government sought to find alternative ways of improving health financing by contracting credit facilities from the donor community.

While this financial intervention was needed, it could still not solve the health financing problem. This situation was unbearable because it led to a shortage of laboratory equipment, medicine, and physicians. Ghana, among other developing countries, adopted the Structural Adjustment Program in 1983. Ghanaians were then responsible for their own healthcare cost. Government raised the user fees for public healthcare services resulting in a purely out-of-pocket payment system well known as the "cash and carry" system. This system marginalized the poor in terms of healthcare utilization. It was a "cash down and get medical attention, or better leave it" situation. Many poor people who could not afford the medical expenses were left to their own fate. Thus, they were left at the mercy of nature: continued suffering or died at worse. Those who were fortunate enough to receive treatment but could pay were detained, and were forced to do menial work, and or plan to escape. This was quite problematic. Healthcare utilization declined. The government became unpopular and had to seek alternative ways of financing healthcare. 
The Non-Governmental Organization (NGO)-initiated Community-Based Health Insurance Schemes (CBHIS), which was launched in 1990. By 2003, there were about 168 mutual Health Organizations, which covered only $1 \%$ of the population. Unfortunately, this scheme failed to address the primary objectives for its establishment. It did not ensure enough government support in order to cater for the poor (Boakye, 2016).

Recognizing the financial burden the "cash and carry" system put on Ghanaians, the New Patriotic Party (NPP) that was an opposition party at that time used it as a major campaign message to introduce a National Health Insurance Scheme when voted into power. Upon winning the December 2000 general elections, the new government (NPP) set up an inter-ministerial task force to harness ideas from all stakeholders (Boakye, 2016). Based on the task force's recommendation, an Act of Parliament was passed in 2003 (Act 650) leading to the establishment of the National Health Insurance Scheme (NHIS). It is administered by the National Health Insurance Authority (NHIA), which was also established under the same Act. However, in the year 2012, NHIA succeeded in replacing the National Health Insurance Act, 2003 (Act 650) with the National Health Insurance Act, 2012 (Act 852). The purpose for this was to integrate all hitherto semiautonomous District-wide Mutual Health Insurance Schemes into a Single Payer System (NHIA, 2013). The main objective of the health insurance is to provide social health insurance for all residents of Ghana by making sure that individuals access healthcare without difficulties, ensuring patient satisfaction and improved health status, thereby trying to achieve the universal health insurance coverage.

The National Health Insurance Fund (NHIF) was set by Act 650 with the main objective of providing funds to subsidize the health cost of members of the district mutual health insurance scheme. Instead of subsidizing the health cost of members of under the district mutual health insurance scheme, the NHIF was reprogrammed to pay for the healthcare cost of members of the NHIS.

According to Boakye (2016), the sources of finance include the following:

a. The National Health Insurance Levy (NHIL). This is $2.5 \%$ VAT on all goods and services.

b. $2.5 \%$ of workers' contribution to the basic Social Security and National Insurance Trust (SSNIT).

c. Monies that are allocated by parliament to the Fund.

d. Returns on investment by the Fund.

e. Grants, donations, gifts from donor communities and volunteers.

f. Fees charged by the National Health Insurance Authority (NHIA) in discharging its duties.

g. Premiums paid by members to the scheme.

h. Money accruing under section 198 of the Insurance Act, 2006 (Act 742), which is a percentage of the emergency motor insurance premium.

The National Health Insurance Levy of 2.5\% VAT together with the $2.5 \%$ of each person's contribution to the National Basic Social Security Scheme constitute earmarked funds and account for more than $90 \%$ of revenue to the Fund. The National Insurance Levy that constitutes 2.5 VAT is the largest source of funding of the scheme accounting for 70 of the revenue (Blanchet et al., 2012). Funds accrued by the NHIF is to pay for claims made by healthcare providers for providing healthcare to members of the scheme. The NHIF is also to pay for administrative expenses of NHIA.

The scheme was supposed to pay the full cost of treatment of subscribers, including medical bills and referrals of over $90 \%$ of all diseases that afflict Ghanaians and are covered under the scheme. However, uninsured patients pay the full cost of treatment. NHIA reported that out-patient utilization has increased by 46 times from 0.6 million in 2005 to 27.4 million in 2013 (Boakye, 2016). The situation is not different from the in-patient utilization that also increased by about 56 times from 28,906 in 2005 to 1.6 million in 2013. Just as healthcare utilization has increased, so are claims payments. Claims payment increased by some 103 times from GHC 7.60 million in 2005 to GHC 785.6 million in 2013.

All resident and non-resident visiting members are eligible to enroll. Membership is not automatic. An individual must go in person to the district NHIS office, complete a registration form, and pay the registration fee and the premium. When duly registered, one is expected to carry a valid ID card in order to be allowed to access healthcare at any healthcare facility. The NHIS packages include payment of health expenses. Currently, there is no co-payment or coinsurance. The scheme exempts certain people from paying the premium: people aged $70+$, children under 18 years, all pregnant women, children in orphanages, beneficiaries of the Livelihood Empowerment Against Poverty (LEAP), persons with disability, mental patients, and leprosaria, among others. NHIA identified some social intervention programs and registered their beneficiaries to one million indigents.

Although Act 852 makes it mandatory for every Ghanaian to register under the scheme, there is no penalty for deciding not to enroll. It is estimated that enrolling onto the scheme would cost households $5.9 \%$ of their expenditure (Boakye, 2016). According to the National Health Insurance Authority, active membership rate is $40 \%$ of the population, which is a huge improvement over the $1 \%$ enrollment rate before the introduction of NHIS in 2003 (NHIA, 2013). All formal sector workers (20\% of the working population) are active members since their premium is deducted at source before they receive their salaries. The challenge now is how to get workers in the informal sector $(80 \%$ of the working population) to enroll since their salaries cannot be deducted at source and are therefore required to pay it directly to the NHIA. By the end of the year 2013, 10.2 million people were enrolled onto the scheme, out of which 5.64 million were renewals, while the remaining 3.24 million represents the new members. NHIS subscription is dominated by young people under 18 years (46.5\%), informal sector employees (33.6\%), indigents $(12.1 \%)$, $70+$ years $(3.8 \%)$, SSNIT contributors $(3.6 \%)$, Military $(0.2 \%)$, and SSNIT pensioners (0.2\%) (NHIA, 2013).

Authorities encourage as many Ghanaians as possible to enroll given the catastrophic effect of out-of-pocket payment. Failure to enroll means paying all medical expenses out-of pocket, taking us back to the dark days of "cash and carry" system. The system that marginalized the poor in terms of healthcare utilization, which was a "cash down and get medical attention, or better leave it" situation. Many poor people who cannot not afford the medical expenses will be left to their own fate.

\section{Methods}

Data source. The source of data for this study is the seventh round of the Ghana Living Standards Survey (GLSS 7), which was conducted in 2016/2017. It is a nationwide household survey designed to generate information on the living conditions in the country at the individual level. The GLSS 7 collects detailed information from households including, health, education, employment and time use, migration, tourism, housing, agriculture, access to finance and asset ownership. A two-stage stratified sampling design was adopted. At the first stage, 1000 enumeration areas (EAs) were selected to form the Primary Sampling Unit (PSUs, giving a sample size of 15,000 households and about 53,000 individuals. Section three (3) of Part A of the questionnaire asks information about individual's health status. This is the population of study. 


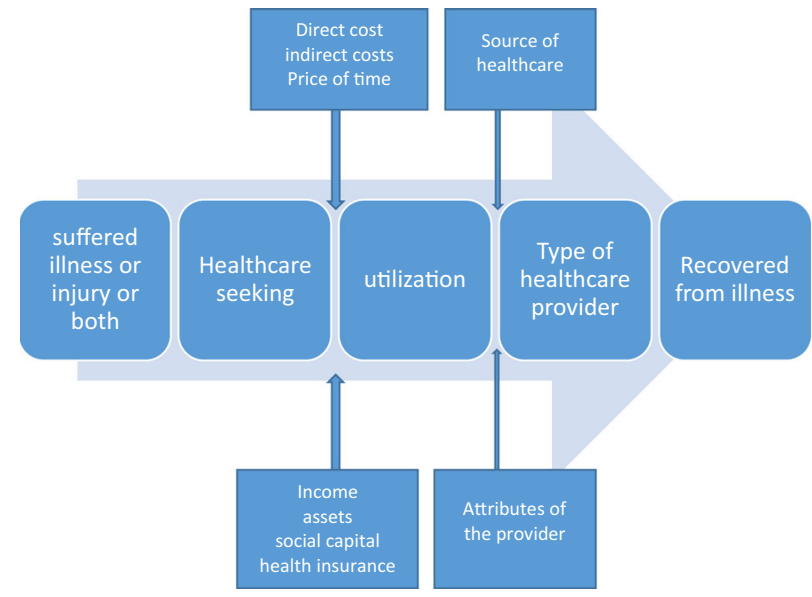

Fig. 1 Conceptualization of demand for healthcare. The concept of demand for healthcare showing the journey from when an individual is experiencing ill-health to when he/she is fully recovered. In between these two extreme ends, the individual has certain decisions to make. First, the decision to seek healthcare or not. Second, if the individual decides to seek healthcare, they must pay the direct cost and indirect cost associated with the healthcare seeking behavior. The direct costs includes the cost of treatment, often measured by out-of-pocket payment (amount paid for folder, diagnosis, drugs, and treatment, hospital stay, any other payment) and the indirect costs includes travel time, travel cost, and waiting time. The presence of health insurance helps to reduce the cost of treatment.

The study design. The proposed this framework for the study as shown on Fig. 1. The concept as depicted on Fig. 1, begins from when an individual is reported to have suffered from illness, or injury or both in the two weeks preceding the interview. The person takes a decision to either seek healthcare or not. Before the individual can utilize the healthcare, there are direct cost and indirect cost that must be paid. The direct cost includes the cost of treatment, often measured by out-of-pocket payment (amount paid for folder, diagnosis, drugs, and treatment, hospital stay, any other payment) and the indirect costs includes travel cost, travel time and waiting time. The presence of health insurance helps to reduce the cost of treatment.

Why do people demand health insurance? To answer this question, there is the need to understand how risks and uncertainties affect demand for health insurance. The standard utility theory assumes certainty of events. However, the fact that some events are uncertain causes us to change our standard utility theory. In the real world, the occurrence of illness is so uncertain.

The von Neumann-Morgenstern utility function shows the decision maker's preference with respect to risk. It says the rational consumer will choose the course of action that has the highest expected utility. It indicates how we convert wealth into utility, accounting for different states individual's development (Nketiah-Amponsah and Sarkodie, 2014). A simple form of expected utility theory assumes that a consumer's utility, $U$, is a function of disposable income, $Y$. Assuming there is a probability, $p$, that the consumer will become ill and spend $L$ on medical care. Alternatively, assume a health insurance context, the consumer could purchase full insurance coverage for the actuarially fair premium of $P=p L$, for which the consumer would receive a payoff transfer, $I=L$, if sickness strikes.

Expected utility without insurance (EU) is given by,

$$
E U_{O I}=(1-p) U(Y)+p U(Y-L)
$$

where EU is expected utility, $(1-p)$ is the probability of not sick, $p$ is the probability of getting sick, and $(Y-L)$ is remaining income after paying medical bills.
While expected utility (EU) with insurance is,

$$
E U_{I}=(1-p) U(Y-P)+p U(Y-L+I-P)=U(Y-P)
$$

A consumer will prefer to buy insurance if the marginal utility of income is declining, i.e., if

$$
\begin{gathered}
\mathrm{EU}_{I}>\mathrm{EU}_{O I} \\
U(Y-P)>(1-p) U(Y)+p U(Y-L)
\end{gathered}
$$

The consumer's choice is between certain losses and uncertain actuarially-equivalent losses. If the consumer buys insurance, it is as if insurance is demanded because of the certainty it provides. Actuarially fair insurance policy means the expected benefits paid out by the insurance company are equal to the premiums taken in by the company. In reality, insurance companies must cover administration and transaction cost-loading. Risk attitude is at the center of the decision to buy any type of insurance. Individual's risk attitude is the key determinant of demand for health insurance. A risk-averse person is more likely to insure. A risk lover is less likely to insure, while a neutral person is indifferent about insuring or not insuring.

In conclusion, a risk lover facing convex utility function has an expected utility without insurance greater than the expected utility with insurance. In contrast, the risk averse person who is faced with concave utility function gets an expected utility with insurance, which is greater than the expected utility without insurance. The most prominent factors that affect demand for health insurance are the probability of illness, cost of illness, degree of risk aversion, income/wealth, and price. Other socioeconomic and cultural factors/religious factors like geographical location, social capital/networking, and access to information.

The estimation technique. The technique for this study is the Propensity Score Matching. The formal treatment follows from the potential outcome approach or the Roy-Rubin Model [(Roy, 1951); Rubin (1974)], which was adopted by Caliendo and Kopeinig (2005). In this paper, the potential outcome refers to the utilization of healthcare, while treatment refers to insured. The main pillars of the model are individuals, insurance and healthcare utilization. Suppose a binary outcome insurance $T$, and healthcare utilization outcome $Y$, and background characteristics, $X$. The background characteristics are age, income, education, sex, and location of residence. The propensity score is defined as the conditional probability of insurance given background characteristic $X$. In case of a binary estimator, the insured indicator $\mathrm{Ti}$ is equal to 1 if the individual is insured and 0 if otherwise. The potential outcome (utilization) is then given as $\mathrm{Yi}$ (Ti) for each individual $i$, where $i=1, \ldots, N$ and $N$ denote total population. The treatment effect (effect of insurance) can then be given as:

$$
\pi_{i}=Y_{i}(1)-Y_{i}(0)
$$

The conditional independent assumption based on propensity score can be written as:

$$
Y(0), Y(1)+T \mid P(X), \vee X
$$

Another requirement besides the independence is what is called the common support or the overlap. This requirement rules out perfect predictability of $T$ given $X$ :

$$
0<P(T=1 \mid X)<1
$$

which means that an individual with the same $X$ has the positive probability of being either insured or uninsured.

Given that conditional independent and the common support assumptions hold, the Propensity Score estimator for ATT can be 
Table 1 Variable description.

\begin{tabular}{|c|c|c|}
\hline Variable & Definition & Description \\
\hline Utilization & Seek treatment & $\begin{array}{l}\text { Binary outcome taking the value of } 1 \text { if } \\
\text { treated, and } 0 \text { if otherwise }\end{array}$ \\
\hline Types of healthcare & $\begin{array}{l}\text { Where the patient seek treatment: whether it is public health facility, private, or } \\
\text { alternative (herbalist and traditionalist) }\end{array}$ & Categorical \\
\hline Health insurance & $\begin{array}{l}\text { Holding health insurance card and have renewed their insurance. This may refer to } \\
\text { active membership. }\end{array}$ & $\begin{array}{l}\text { Binary taking the value of } 1 \text { if insured, and } \\
0 \text { if otherwise. }\end{array}$ \\
\hline $\begin{array}{l}\text { Out-of-pocket } \\
\text { payment }\end{array}$ & The cost of treatment (amount paid for folder, consultation, drugs, etc) & Continuous \\
\hline Age & the age of the respondent, & Continuous \\
\hline Income & respondent's monthly income from the main occupation, & Continuous \\
\hline Education & $\begin{array}{l}\text { The highest educational attainment of the respondent categorized into none (no } \\
\text { education), those who completed primary (from class one to class six), Junior High } \\
\text { School, Senior High School, and tertiary or higher education. }\end{array}$ & Categorical \\
\hline Location & The area of residence is also grouped into rural and urban. & Categorical \\
\hline Sex & The sex of the individual grouped into Male and Female. & Categorical \\
\hline
\end{tabular}

written as:

$\pi_{\mathrm{ATT}}^{\mathrm{PSM}}=E_{P(X) \mid T=1}\{E[Y(1) \mid T=1, P(X)]-E[Y(0) \mid T=0, P(X)]\}$

Put in words, the propensity score matching (PSM) estimator is simply the mean difference in utilization over the common support, approximately weighted by the propensity score distribution of participants.

Put in simple econometrics form:

$$
Y_{i}=\alpha+\beta T_{i}+\delta X_{i}+\varepsilon_{i}
$$

where $Y_{t}$ is the various measures of utilization. That is to utilize healthcare if suffered illness or injury or both, and whether it is a public, private, or alternative healthcare provider. $\alpha$ is the autonomous effects; $T_{i}$ is the insurance status dichotomized into insured and uninsured. $X_{i}$ is the background covariates, which includes age, income, education, sex, and location. $\varepsilon_{i}$ is the error term.

Description of all variables are contained in the Table below (Table 1).

The application of the propensity score matching (PSM) method requires that estimations are made to verify if the health insurance status has any implication for differences in background characteristics or not. In other words, do the background characteristics differ between insured groups and uninsured groups? The PSM model matches those characteristics and make sure the observations are as similar as possible, before comparing their outcomes using the propensity score matching method.

\section{Results}

Summary statistics of the variables. Close to half (46\%) of the sample did not seek healthcare when ill. About $52 \%$ of the sample is insured, while $48 \%$ are not insured. The average age is 25 years, showing clearly that the sampled people are very young. The average monthly income is GHC 990.64 (\$ 170.8, using the exchange rate of GHC 5.8/\$1). The average out-of-pocket payment incurred to seek medical treatment is GHC 45.99 ( $(\$ 7.9$, using the exchange rate of GHC 5.8/\$1). The National Health Insurance Scheme (NHIS) covers over $90 \%$ of all diseases in Ghana. When seeking treatment for any of these diseases, there is no co-payment. It is worth noting that about half of the respondents said they paid the medical bill themselves. In terms of the highest educational qualification, $16 \%$ of the respondents did not have any educational qualification, 35\% have a primary level as their highest educational level. The remaining are JSS/JHS/Middle (28\%), SHS (14\%) and tertiary level (7\%). In terms of location of residence, there are more people living in the urban areas (51\%) than rural area (49\%). This is the evidence of urbanization (See Table 2).
Table 2 Descriptive statistics of the dependent and independent variables.

\begin{tabular}{|c|c|c|c|}
\hline Dependent variable & Observation & Mean & $\begin{array}{l}\text { Standard } \\
\text { deviation }\end{array}$ \\
\hline Utilization & 8297 & 0.47 & 0.50 \\
\hline \multicolumn{4}{|l|}{ Type of healthcare } \\
\hline No care & 3873 & 0.46 & 0.50 \\
\hline Public modern & 2023 & 0.27 & 0.44 \\
\hline Private modern & 2288 & 0.25 & 0.43 \\
\hline Alternative & 113 & 0.15 & 0.12 \\
\hline \multicolumn{4}{|l|}{ Independent variables } \\
\hline \multicolumn{4}{|l|}{ Health Insurance status } \\
\hline Insured & 30,0473 & 0.53 & 0.50 \\
\hline Uninsured & 28,090 & 0.47 & 0.50 \\
\hline Income & 5021 & 990.64 & 1345 \\
\hline $\begin{array}{l}\text { Out-of-pocket } \\
\text { payment }\end{array}$ & \multicolumn{2}{|c|}{ payment } & 1721 \\
\hline Age & 59,864 & 25.13 & 19.80 \\
\hline \multicolumn{4}{|l|}{ Gender } \\
\hline Male & 29,018 & 0.48 & 0.50 \\
\hline Female & 30,846 & 0.52 & 0.50 \\
\hline \multicolumn{4}{|l|}{ Education } \\
\hline No qualification & 11,058 & 0.16 & 0.4 \\
\hline Primary & 19,298 & 0.35 & 0.5 \\
\hline JSS/ JHS/ Middle & 15,312 & 0.28 & 0.2 \\
\hline Secondary \&Voc\&Tech & 7498 & 0.14 & 0.2 \\
\hline Tertiary & 3350 & 0.07 & 0.1 \\
\hline \multicolumn{4}{|l|}{ Location } \\
\hline Urban & 30,277 & 0.51 & 0.50 \\
\hline Rural & 29,587 & 0.49 & 0.50 \\
\hline
\end{tabular}

Enrollment onto the National Health Insurance Scheme (NHIS). The cross tabulation shows that about $55.7 \%$ of all those who reported to have suffered from illness or injury or both are insured whereas $44.3 \%$ are uninsured. In the previous section, it was reported that more than one-third of the people who suffered from illness or injury or both did not seek healthcare. There is a difference in this number between the two groups under investigation. For those who did not seek healthcare, $45.3 \%$ are insured whereas $54.7 \%$ are uninsured. About $64.9 \%$ of those who consulted a physician are insured, higher than $35.1 \%$ who are uninsured (see Fig. 2).

Although the premium is low and the benefits of enrollment are enormous, some $20.1 \%$ of the population have never been registered with any health insurance whereas $80 \%$ have registered with NHIS or 


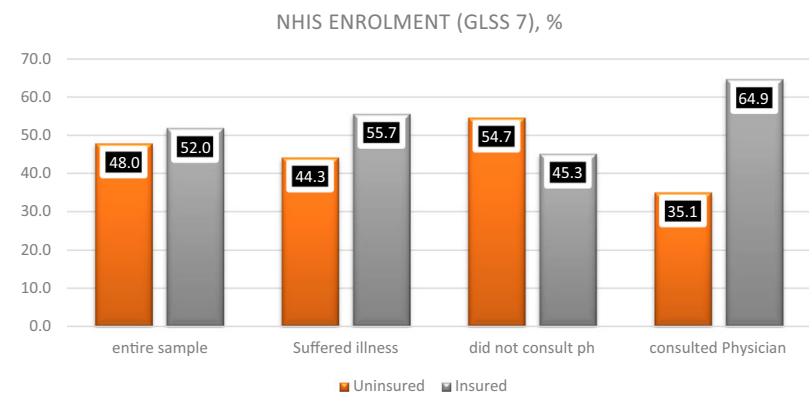

Fig. 2 National Health Insurance Enrollment. This shows the percentage of individuals who are insured and those who are not insured among the respondents (the entire sample). It also indicates the percentages of the sub-groups with respect to those who reported ill-health, those who consulted physicians, and those who did not consult physicians.

$2016 / 2017$

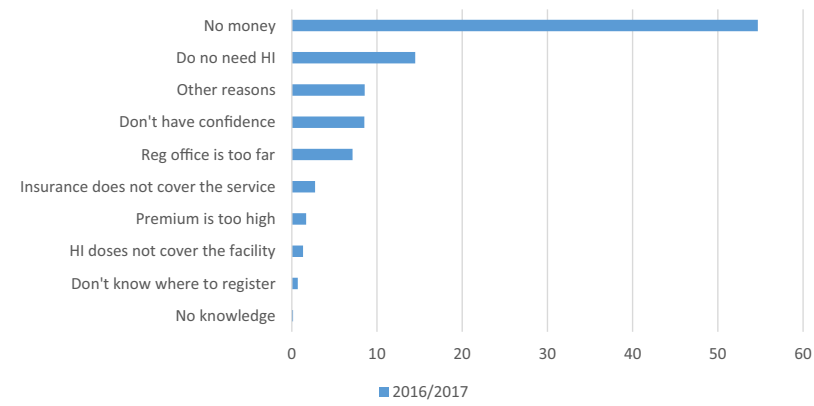

Fig. 3 Reasons why some respondents have never registered. About $48 \%$ of the respondents are not insured, citing various reasons. This Figure depicts the percentages of the various reasons given for not enrolling.

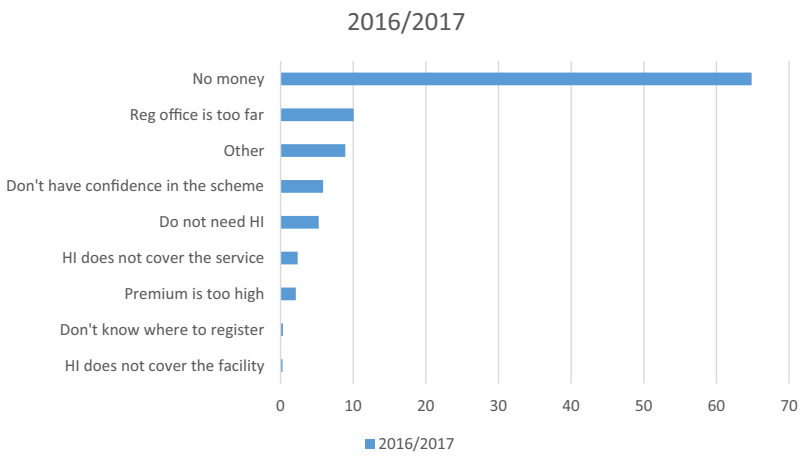

Fig. 4 Reasons for stopping to enroll. This Figure shows the percentages of the over $30 \%$ of all insured persons who had stopped enrolling, citing various reasons for dropping out.

private health insurance or both. When asked why they have never been registered with a health insurance, they cited reasons as No money (54.69\%), do not need health insurance (14.49\%), other $(8.56 \%)$, don not have confidence in operators of the scheme $(8.52 \%)$, among other reasons. These findings are similar to that of Ghana Demographic and Health Survey (GDHS, 2014), which states that those who are not covered by the National Health Insurance Scheme (NHIS) gave reasons as no money (63\%), do not have confidence in the operation of the scheme $(9.6 \%)$, premium is too high $(6.9 \%)$, or registration office is too far (4.3\%) (see Fig. 3). About $30 \%$ of the people who were enrolled have stopped enrolling. They cited reasons as no money $(64.84 \%)$, registration office is too far $(10.07 \%)$, and other reasons (8.9\%), among others (GSS, 2017) (see Fig. 4).
The estimated results of the probit regression show that with the exception of sex and location, the coefficients of all other variables are positive and statistically significant. It can, therefore, be concluded those with higher age, higher income, all the educational categories (no education, Primary, JHS, SHS, and Higher) are more likely to enroll, while males are less likely to enroll. The result is consistent with the findings of NketiahAmponsah (2009) that the decision of women aged 15-49 to participate in public health insurance is influenced by income, age, religion, and access to information. Since these background characteristics have been shown to influence the decision to enroll, there is the need to correct for this problem.

The effect of the National Health Insurance Scheme on healthcare utilization, using the mean graphs. This section looks at the likelihood that enrollment onto the National Health Insurance Scheme (NHIS) increases healthcare utilization. This is measured by the likelihood of seeking healthcare when ill, injured or both. The data reports that $53.07 \%$ of all those who suffered illness or injury or both consulted physicians. About $46.93 \%$ did not seek treatment at all. Those who consulted physician did so from public healthcare provider (24.37\%), private healthcare provider (27.58\%), and alternative healthcare provider (1.6\%). These percentages are the benchmarks for comparison in order to conclude whether or not insurance status has increased healthcare utilization, and from what type of healthcare provider. Insurance status is dichotomized and takes the value of 1 if insured, and 0 if otherwise. The uninsured category also takes the value of 1 if uninsured and 0 if otherwise. If the value of 1 is above (below) the benchmark (which is the horizontal line), then utilization is increased (decreased) (as illustrated on Figs. 5a, b, c, d, and e).

Effect of NHIS on healthcare utilization and out-of-pocket payment: propensity score matching (PSM). As stated already, the method of estimation is the Propensity Score Matching. So then how is the PSM calculated? In the algorithm to estimate the propensity score, the treatment is insurance taking the dummy value of 1 if insured and zero if otherwise. Recall from the previous sections that about $55.7 \%$ of all those who reported to have suffered from illness or injury or both are insured whereas $44.3 \%$ are uninsured. The application of the propensity score matching (PSM) method requires that estimations are made to verify if the health insurance status has any implication for differences in background characteristics or not. In other words, do the background characteristics differ between insured groups and uninsured groups? The statistics of the dependent variables and the background characteristics for both the insured and the uninsured persons are shown on Table 3.

The essence of Table 3 is to provide evidence that the background characteristics differ between insured and uninsured groups. For this reason, there is the need to match those characteristics and make sure the observations are as similar as possible, before comparing their outcomes using the propensity score matching method. The propensity score matching (PSM) model first estimates the probit regression to proof that the background characteristics influence the probability of enrolling in health insurance, as illustrated in Table 4 below.

The process of the PSM is as follows: The estimate shows that the common support option has been selected. The region of common support is $[0.57,0.93]$. The model does not have a propensity that goes as high as 1.00 . The score ranges between 0.57 and 0.93 . The essence of common support is to make sure that only observations that have similar propensity scores are compared in the same range. The description of the estimated propensity score in the region of common support is given below. This estimated propensity score is given in percentiles as shown on Table 5 below.

The final number of blocks identified is 5 . This number of blocks ensure that the mean propensity score is not different 
a

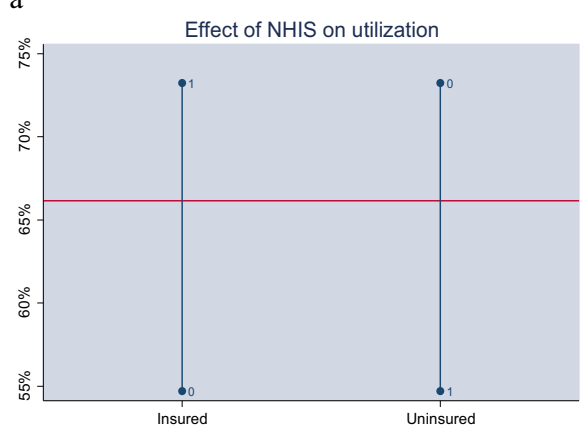

Source: Author's computation based on

GLSS 7

c

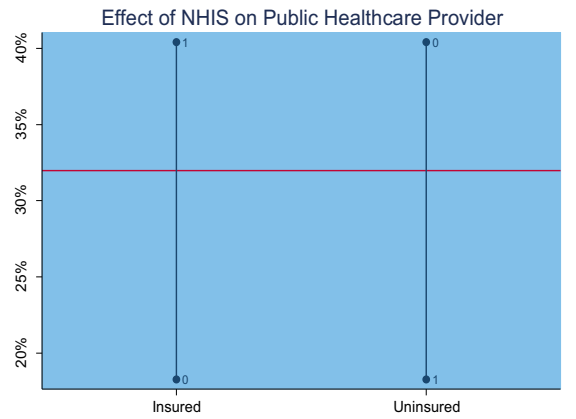

Source: Author's computation based on

GLSS 7

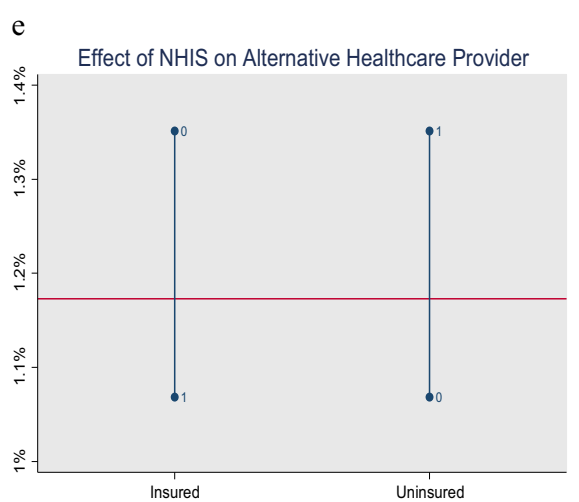

Source: Author's computation based on GLSS

7 b

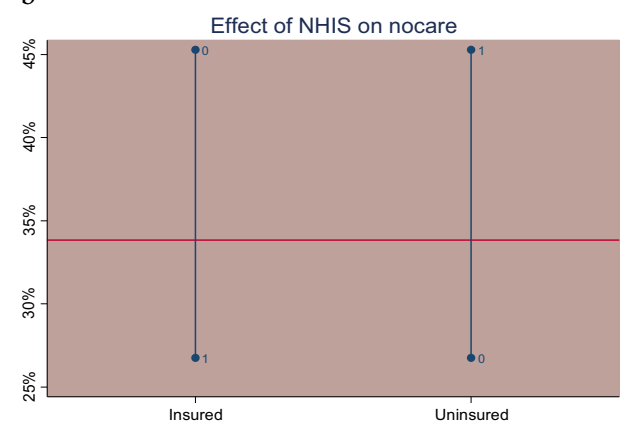

Source: Author's computation based on GLSS

7

d

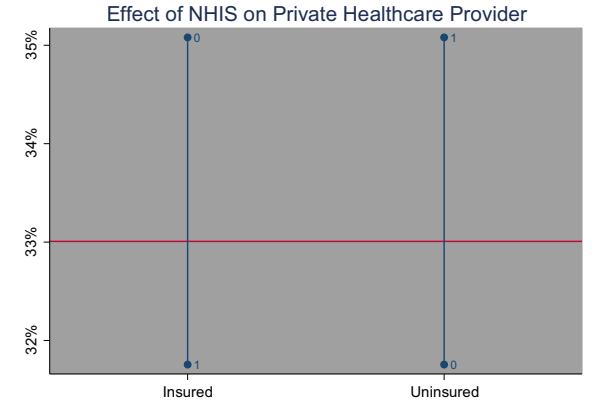

Source: Author's computation based on GLSS

7

Fig. 5 Effect of NHIS on healthcare utilization and the types of healthcare. The effect of the National Health Insurance Scheme on healthcare utilization is shown on Fig. $5 \mathrm{a}$ to $5 \mathrm{e}$. It begins with general healthcare services followed by the types of healthcare-Nocare, Public, Private, and Medical Alternative. It is a mean graph that measures the likelihood of seeking healthcare. The horizontal line is the mean benchmark for healthcare utilization of the sample. The percentages are the benchmarks for comparison in order to conclude whether or not insurance status has increased healthcare utilization, and from what type of healthcare provider. Insurance status is dichotomized and takes the value of 1 if insured, and 0 if otherwise (indicated on the vertical line). The uninsured category also takes the value of 1 if uninsured and 0 if otherwise. If the value of 1 is above (below) the benchmark which is the horizontal line, then utilization is increased (decreased). Details of the Figure are as follows: a: Effect of NHIS on general healthcare services. $\mathbf{b}$ : Effect of NHIS on Nocare. c: Effect of NHIS on Public Healthcare. d: Effect of NHIS on Private Healthcare. e: Effect of NHIS on Medical Alternative Healthcare.

for treated (insured) and controls (uninsured) in each block. The test of balancing properties indicates that the balancing property is satisfied. This means that in each of these blocks, not only are the propensity scores similar, but the background characteristics on which the matching is done are also similar.
The results show the inferior bound, the number of treated and the number of controls for each block (Table 6).

The nearest neighbor matching method is employed for this study to estimate the propensity score matching. It estimates the predicted probability of the propensity score on which the 
Table 3 Summary statistics of the dependent variables and background characteristics for the uninsured and insured groups.

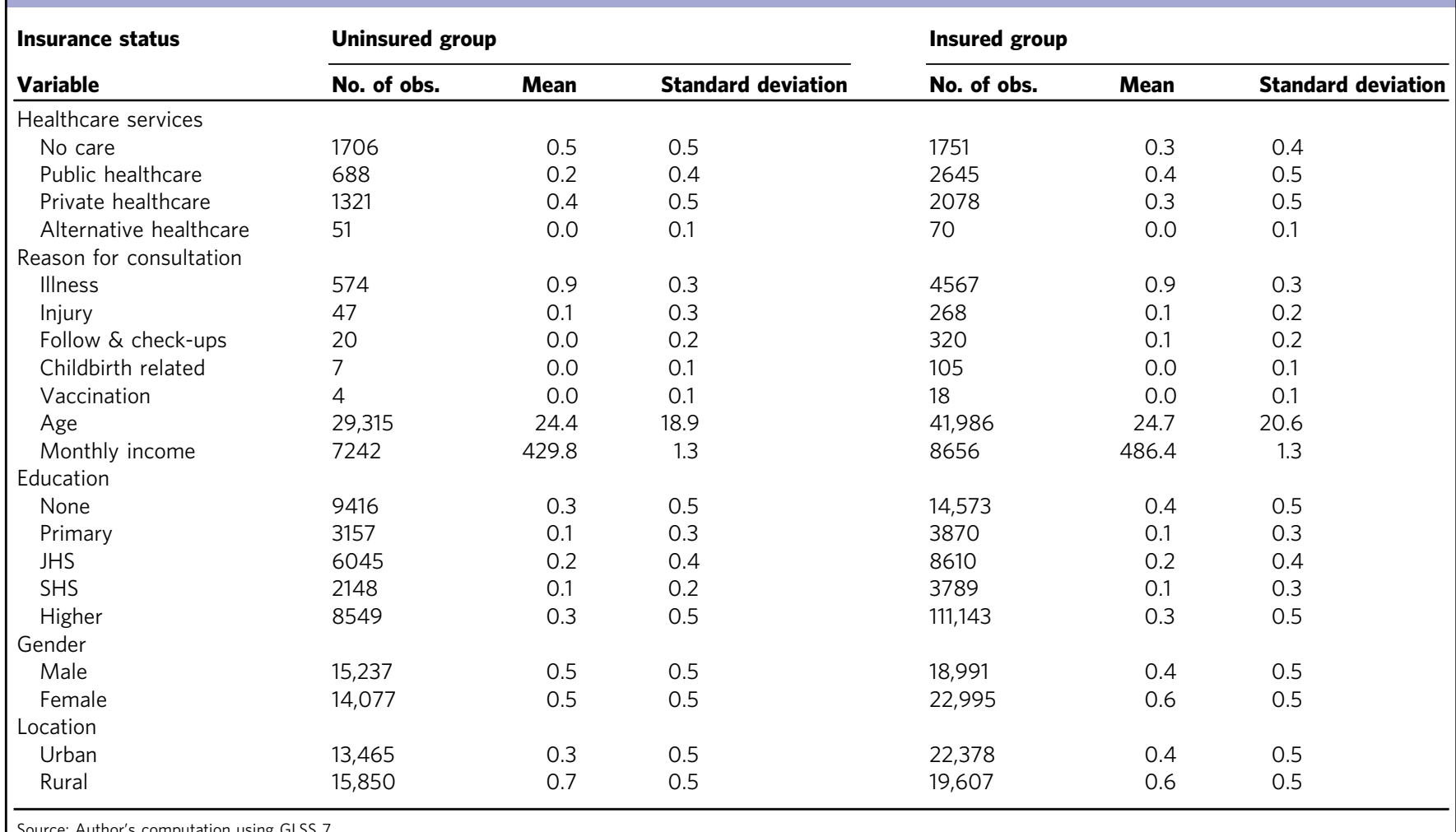

Source: Author's computation using GLSS 7.

\begin{tabular}{|c|c|c|c|c|}
\hline & Coefficient & Std. error & $z$ & $p>|z|$ \\
\hline Age & 0.005 & 0.0010 & 5.22 & 0.000 \\
\hline Income & 0.05 & 0.012 & 4.89 & 0.000 \\
\hline \multicolumn{5}{|l|}{ Education } \\
\hline None & 0.182 & 0.061 & 2.96 & 0.003 \\
\hline Primary & 0.278 & 0.052 & 5.36 & 0.000 \\
\hline $\mathrm{JHS}$ & 0.385 & 0.062 & 6.21 & 0.000 \\
\hline \multicolumn{5}{|l|}{ SHS (ref) } \\
\hline Higher & 0.284 & 0.053 & 5.39 & 0.000 \\
\hline \multicolumn{5}{|l|}{ Gender } \\
\hline $\begin{array}{l}\text { Male } \\
\text { Female (ref) }\end{array}$ & -0.126 & 0.030 & -4.17 & 0.000 \\
\hline \multicolumn{5}{|l|}{ Location } \\
\hline \multicolumn{5}{|l|}{ Urban (ref) } \\
\hline Rural & -0.047 & 0.030 & -1.54 & 0.124 \\
\hline Constant & 0.234 & 0.088 & 2.66 & 0.000 \\
\hline
\end{tabular}

matching is done. It estimates the nearest neighbor of each treated unit and reports the bootstrapped standard errors. After bootstrapping ${ }^{1}$ the effect is the same. However, the standard errors have been reduced and the difference is statistically significant. The difference between the outcome on the insured and the outcome on the uninsured after matching is measured by Average Treated Effect (ATET) on the treated. It is interpreted that if someone is insured, his/her likelihood of healthcare utilization will be increased by the ATET coefficient (See Table 7).
Table 5 Estimated propensity score in percentiles.

\begin{tabular}{llll} 
& Percentiles & Smallest & \\
\hline $1 \%$ & 0.7 & 0.6 & \\
$5 \%$ & 0.7 & 0.6 & Observations $=10,486$ \\
$10 \%$ & 0.8 & 0.6 & Sum of Wgt $=10,486$ \\
$25 \%$ & 0.8 & 0.6 & Mean $=0.82$ \\
$50 \%$ & 0.8 & & Standard deviation $=0.04$ \\
$75 \%$ & 0.9 & 0.9 & Variance $=0.002$ \\
$90 \%$ & 0.9 & 0.9 & Skewness $=-1.11$ \\
$95 \%$ & 0.9 & 0.9 & Kurtosis $=4.82$ \\
$99 \%$ & 0.9 & 0.9 & \\
\hline Source: Author's calculation using GLSS 7. & \\
\hline
\end{tabular}

Table 6 The number of blocks in propensity score.

\begin{tabular}{llll}
\multirow{2}{*}{ Inferior of block of pscore } & \multicolumn{2}{l}{ Insurance status } & \multirow{2}{*}{ Total } \\
\cline { 2 - 3 } & Uninsured & Insured & \\
\hline 0.4 & 0 & 2 & 2 \\
0.6 & 551 & 215 & 2215 \\
0.8 & 903 & 1664 & 5210 \\
0.8 & 368 & 4307 & 3001 \\
0.9 & 8 & 2633 & 58 \\
Total & 1830 & 8656 & 10,486 \\
\hline $\begin{array}{l}\text { Note: In this case, the common support option has been selected. } \\
\text { Source: Author's calculation using GLSS 7. }\end{array}$ & \\
\hline
\end{tabular}


Table 7 Propensity score matching of the effect of NHIS on healthcare utilization (by types) and out-of-pocket payment.

\begin{tabular}{|c|c|c|}
\hline Dependent variable & $\begin{array}{l}\text { Average treatment Al robust } \\
\text { effect (ATET) }\end{array}$ & Standard error \\
\hline General healthcare & $0.26^{\star \star \star}$ & 0.059 \\
\hline No care & $-0.26^{\star \star \star}$ & 0.059 \\
\hline Public healthcare & $0.19^{\star \star \star}$ & 0.035 \\
\hline Private healthcare & $0.10^{\star \star}$ & 0.052 \\
\hline $\begin{array}{l}\text { Alternative } \\
\text { healthcare }\end{array}$ & $-0.04^{\star}$ & 0.022 \\
\hline $\begin{array}{l}\text { Out-of-pocket } \\
\text { payment }\end{array}$ & 0.04 & 0.258 \\
\hline
\end{tabular}

The PSM regression estimates were done in groups beginning from general healthcare seeking behavior and then repeated on each of the different types of healthcare provider. The results indicate that the Average Treatment Effect (ATET) is 0.26 for general healthcare utilization. This means that the National Health Insurance Scheme increases the probability of healthcare utilization by 0.26 . In other words, the treatment group (the insured) are $26 \%$ more likely to seek treatment when ill than the controlled group (the uninsured). The ATET coefficient for nocare is the -0.26 . For the various types of healthcare providers, the ATET coefficient for Public, Private, and Alternative are $0.19,0.10$, and -0.04 . This can be interpreted as NHIS increases utilization of healthcare provided by the Public, Private by 19 and $10 \%$ respectively but decreases Alternative healthcare by $4 \%$. With regards to the effect on out-of-pocket payment, the coefficient is 0.04 , which means that enrolling onto the NHIS reduces the amount of money patients pay out of their pockets to receive treatment by only $4 \%$.

\section{Discussion}

The active membership of health insurance in Ghana stands at 52\%. This number increases to 55.7 when we sample those who suffered from illness or injury or both. This means close to half of the Ghanaian population are not enrolled onto any kind of health insurance. Though the literature confirms that health insurance increases healthcare utilization, about one-fifth of the people interviewed had never been enrolled onto any health insurance scheme, citing reasons as no money, no need for health insurance, and no confidence in the system. Even those who enrolled about $30 \%$ of them had dropped out, giving no money, no confidence, and high premium as reasons for dropping pout. This finding is puzzling since Authorities of the National Health Insurance Scheme have indicated that they have done everything possible to encourage the poor and vulnerable to enroll. Interventions such as charging a lower premium, and free registration for children and the aged, sponsored-registration by some benevolent individuals were all initiated to increase enrollment by the poor. The findings from this study clearly show that the interventions by the Authorities to increase enrollment by the poor are not yielding the expected results as it is still the rich who are more likely to enroll. Most people do not see the need to have a health insurance. According to the NHIA, the premium charged constituted a small percentage of the sources of funds. If the premium charged contributes very little to funds but at the same time it prevents people from active participation in the health insurance scheme, then it must be abolished.

The propensity score matching (PSM) model estimated using the probit regression, the determinants of enrolling onto the health insurance. The PSM model identified age, income, education, sex and location of residence as key determinants of enrolling onto health insurance in Ghana. The older people, people with higher income, those who are highly educated, females and urban dwellers are more likely to enroll.

The mean graph was used to show whether or not health insurance increases utilization. The benchmark is the mean mark of seeking healthcare which is about $53.07 \%$. It can be concluded that NHIS is likely to increase healthcare utilization (see Fig. 5a). Extending the discussion to cover those who did not seek healthcare, and also the type of healthcare provider chosen, Fig. $4 \mathrm{~b}$ shows that insurance increases the likelihood of consulting a physician when sick, and also increases the chances of seeking public healthcare. However, enrollment onto a health insurance scheme decreases the likelihood of choosing no care, private healthcare and alternative healthcare.

The PSM regression results also confirms that enrolling onto the National Health Insurance Scheme increases healthcare utilization by $26 \%$ for the insured. The NHIS enrollment decreases nocare by the same percentage suggesting that insured are likely not to do nocare but seek treatment when ill or injured. In terms of the types of healthcare providers, it is found that insured persons are more likely to increase their utilization of healthcare providers by from the public and private sectors, decreases Alternative healthcare utilization. The negative effect of health insurance on Alternative Healthcare may be due to patients' preference of the other types of healthcare over. Perhaps in the past, they were seeking treatment from the Alternative healthcare provider (traditionalist, spiritualist, homeopathy) because they could not afford the other types. However, now because of the presence of a health insurance, they can afford the other types and therefore prefer them.

Out-of-pocket payment is measured by fees paid for folder, diagnosis, drugs and treatment, hospital stay, and any other payment. The average treatment effect of NHIS on out-of-pocket payment is -0.04 . Though not statistically significant, having NHIS card rather increases out-of-pocket payment. This might be due to the fact that even though there is no co-payment, some unscrupulous healthcare providers demand some cash payment before administering treatment to their patients.

\section{Conclusion and policy recommendation}

The results show that $52 \%$ of the population had been insured, $20 \%$ had never been insured and the almost 30\% stopped enrolling, making the percentage of the population without a valid NHIS card as $48 \%$. Lack of finance is the major reason why some people are not enrolled on one hand, and for not continuing to enroll on the other hand. The estimates show that NHIS enrollment increases healthcare utilization, but have insignificant effect on out-of-pocket payment.

Based on the findings, the following recommendations are made to policymakers in order to increase the National Health Insurance Scheme enrollment, healthcare utilization and sustainability of the scheme.

1. Any policy to increases enrollment must be targeted at the youth, the poor, the non-educated, males, and rural dwellers. In general, NHIS increases healthcare utilization. Ghanaians must be sensitized and encouraged to enroll. People who are not enrolled do so because there is no money to pay subscription, and also, they do not trust the NHIS system.

2. Abolish the premium in order to increase enrollment.

3. Ghana can learn from other systems by realigning its public expenditure and give priority to healthcare expenditure. Again, the government of Ghana can make enrollment compulsory by making the health insurance card a requirement for accessing certain public services such as vehicle and license registration, passport acquisition, accessing free Senior High School education (as it is the case with TIN), among others. 
In general, policy makers must educate on the need for health insurance to cushion them in times of trouble.

4. A greater number of people had not been insured and about one-third did not renew their insurance card. They gave the reason as "no money" for their inability to stay insured. This finding is puzzling since Authorities of the National Health Insurance Scheme have indicated that they have done everything possible to encourage the poor and vulnerable to enroll. In order to reduce this huge dropout from NHIS and ensure that the healthcare system in Ghana becomes more propoor, government can encourage benevolent individuals who paid to register the vulnerable in society to help them renew their membership cards. More than half of the respondents pay a greater part of the medical cost.

5. Policymakers must institute measures to reinvigorate citizens' trust in the scheme. The essence is to ensure acceptance of NHIS by providers. The National Health Insurance Authority (NHIA) is therefore encouraged to improve the NHIS systems in order to win the trust of Ghanaians as stated in the previous paragraph.

\section{Data availability}

I used a secondary data from the seventh edition of the Ghana Living Standards Survey (GLSS 7), which was conducted in 2016/ 2017. The data is available and can be sourced from the Ghana Statistical Service.

Received: 22 December 2020; Accepted: 5 November 2021; Published online: 23 November 2021

\section{Note}

1 This is the robustness check of the estimates

\section{References}

Blanchet NJ, Fink G, Osie-Akoto I (2012) The effect of Ghana's National Health Insurance scheme on healthcare utilization. Ghana Med J, 46(2), 76-84.

Boakye S (2016) Revenue Earmarking in Ghana: Management and Performance Issues. Institute for Fiscal Studies, Occassional Paper No. 07

Caliendo M, Kopeinig S (2005) Some practical guidance for the implementation of propensity score matching. Discussion Paper Series, IZA DP(1588)

Card D, Donkin C, Maetoas N (2012) The impact of nearly universal insurance coverage on health care utilization and health: evidence from medicare. Am Econ Rev 98(5):42-58

Dong Y (2011) How health insurance affects health care demand - a structural analysis behavioural moral hazard and adverse selection. Econ Inquiry 51(2):132-1344

Duku SK, Asenso-Boadi F, Nketiah-Amponsah E, Arhinful DK (2016) Utilization of healthcare services and renewal of health insurance membership: evidence of adverse selection in Ghana. Health Econ Rev 6:43

Gajate-Garrido, Ahiadeke C (2012) The effect of parents' insurance enrolment on health care utilization: evidence from Ghana. Available at SSRN: http:// ssrn.com/abstract $=2158824$

Gajate-Garrido, Ahiadeke C (2015) Gajate-Garrid The Effect of insurance Enrolment on Maternal and child Health Care Utilization: The case of Ghana. Available at SSRN: http://ssrn.com/abstract. Retrieved September 1st, 2016

Ghana Statistical Service (2017) Ghana Living Standards Survey, GLSS 7. Ghana Statistical Service, Accra

Ibiwoye A, Adeleke A (2007) The impact of health insurance on health care provision in developing countries. Ghana J Dev Stud 14(21):49-58

Jutting, J.P. (2001) The impact of health insurance on the access to health care and financial protection in rural development countries: the example of Senegal. Health Nutrition and Population Discussion Paper 4

Lambon-Quayefio M, Owoo NS (2017) Determinants and impact of the National Health Insurance on neonatal mortality in Ghana. Health Econ Rev 7:34

National Health Insurance Authority (2013) National Health Insurance Annual Report. National Health Insurance Authority, Accra, Ghana
Nketiah-Amponsah E (2009) Demand for health insurance among women in Ghana: cross sectional evidence. Int Res J Finan Econ 33:179-191

Nketiah-Amponsah E, Arthur E (2013) Choice of delivery facility among expectant mothers in Ghana: does access to health insurance matter? J Health Manag 15(4):509-524

Nketiah-Amponsah E, Sarkodie AO (2014) Choice of Healthcare Provider in Ghana: Empirical Evidence. In: Twerefou DK, Quartey P, Boakye-Yiadom L, Baah-Boateng W eds Readings on key economic issues in Ghana. Digibooks Ghana Ltd. Social Science, Accra

Owoo NS, Lambon-Quayefio MP (2013) National health insurance, social influence and antenatal care use in Ghana. Health Econ 3:19

Roy A (1951) Some thoughts on the distribution of earnnings. Oxford Econ Paper 3:135-145

Rubin D (1974) Estimating causal effects to treatment in randomised and nonrandomised studies. J Educ Psychol 66:688-701

Saksena P, Antunes AF, Xu K, Musango L, Carrin G (2010) Impact of mutual health insurance on access to health care and financial risk protection in Rwanda. World Health Report (2010) Background Paper, No 6

Sekyi S, Domanban PB (2012) The effects of health insurance on outpatient utilization and healthcare expenditure in Ghana. Int J Human Soc Sci 2(10):76-85

Spaan E, Mathijssen J, Tromp N, McBain F, ten Have A, Baltussen R (2012) The impact of health insurance in Africa and Asia: a systematic review. Bull World Health Organiz 90:685-692

Wang W, Temsah G, Mallick L (2017) The impact of health Insurance on maternal health care utilization: evidence from Ghana, Indonesia and Rwanda. Health Policy Plann 32(3):366-375

Witter S, Garshong B (2009) Someting old or something new? Social health insurance in Ghana. BMC Int Health Hum Right 9:20

World Health Organization (2013) Country Statistics. World Health Organization, Ghana

Xiao E (2011) The effect of health insurance on health care spending in young adults

\section{Acknowledgements}

I declare that with the exception of references to other people's work, which have dully been acknowledged, this research article is my own work. I am responsible for the entire write up. I did not receive any financial support for this research article.

\section{Competing interests}

The author declares no competing interests.

\section{Ethical approval}

I used secondary data (data already collected by Ghana Statistical Service). Therefore, I do not need ethical approval.

\section{Informed consent}

I used secondary data (data already collected by Ghana Statistical Service). Therefore, I do not have any informed consent.

\section{Additional information}

Correspondence and requests for materials should be addressed to Adu Owusu Sarkodie.

Reprints and permission information is available at http://www.nature.com/reprints

Publisher's note Springer Nature remains neutral with regard to jurisdictional claims in published maps and institutional affiliations.

Open Access This article is licensed under a Creative Commons Attribution 4.0 International License, which permits use, sharing, adaptation, distribution and reproduction in any medium or format, as long as you give appropriate credit to the original author(s) and the source, provide a link to the Creative Commons license, and indicate if changes were made. The images or other third party material in this article are included in the article's Creative Commons license, unless indicated otherwise in a credit line to the material. If material is not included in the article's Creative Commons license and your intended use is not permitted by statutory regulation or exceeds the permitted use, you will need to obtain permission directly from the copyright holder. To view a copy of this license, visit http://creativecommons.org/ licenses/by/4.0/.

(c) The Author(s) 2021 